\title{
Household investment behavior toward urban flooding adaptation in Ho Chi Minh City
}

\author{
LE THANH NHAN ${ }^{a}$ \\ ${ }^{a}$ University of Economics Ho Chi Minh City
}

\begin{abstract}
A R T I C L E I N F O
A B S T R A C T

Received: 14 Jul, 2017

Revised: 29 Aug, 2017

Accepted 2 Oct, 2018

Available online

JEL classification:

Q54, R29, D10

An investigation about the adaptive capacity of residents in $\mathrm{Ho}$ Chi Minh City when facing the flooding problems which have frequently happened in recent years. Although the government has spent a lot of money in the drainage system, and the situation has been reported to be better, a high proportion of surveyed people said that the improvement is just local; however, the whole city still needs more effort to control flooding. Households living closely to frequently flood-prone usually consider two main measures to protect themselves from the flood: Floor elevation or dry-proof investment. Since housing is a big money while their income is still low, moving to another place seems to be inapplicable. Doing almost nothing and leaning on the public projects are still the main strategy.
\end{abstract}

\section{Keywords}

Urban floods;

Adaptation;

Household investment.

\footnotetext{
a nhanlt@ueh.edu.vn

Please cite this article as: Le, T. N. (2018). Household investment behavior toward urban flooding adaptation in Ho Chi Minh City. Journal of Asian Business and Economic Studies, 25(S02), 112-128.
} 


\section{Introduction}

As the biggest and most important center in Vietnam, Ho Chi Minh City (HCMC) has a population of 8 million with a density of 3,800 people per kilometer square. Rapid economic development is one of the good signs of this city, but many other problems also occurred when the development of infrastructure cannot catch up with the speedy urbanization rate of HCMC. The inconsistency in the urban development in HCMC caused various problems, one of which is the rainfall exceeding the capacity of the urban sewer and drainage system, one of the reasons for major urban flooding (Dao, 2009). In addition, frequent flooding in HCMC is also a consequence of tides and high discharges from surrounding rivers, such as Sai Gon River and Dong Nai River, where the situation especially becomes more severe when there is intense rainfall in the region.

Urban flooding has had considerable impact on the living standard in HCMC. The city is at serious risk of flooding, from not only regular but also extreme climatic events such as tropical storms and typhoons (Asian Development Bank, 2010). In recent years, despite indefatigable efforts made by the local authorities, urban flooding has caused many difficulties for people there, especially in the rainy season (Nguyen, 2011). Moreover, according to a report from the Steering Centre for Urban Flood Control Program (SCFC) (2013), insufficient capacity and inefficient management are also important reasons as to why the problem worsened and current projects are far from effective, in addition to inefficiency of the drainage system, elevations of the city and land subsidence, inadequate spatial planning, policies, and regulations, and lack of public awareness and participation, which all have aggravated the flooding problem (SCFC, 2013). In economic terms, the current flooding in HCMC has caused significant economic damage and impacted the health of HCMC inhabitants. An estimated amount of economic damage caused by flooding every year ranges from VND 6,000 billion to 22,000 billion (SCFC, 2013).

Therefore, devising good strategies and well-prepared plan to adapt to urban flooding problems will help HCMC to cope with risks from natural disaster, which partially contributes to sustainable development goals. There are several components within adaptive strategy; comprehending them will help develop and operate adaptive plans efficiently.

To reduce impacts of urban flooding and their vulnerability is one of the leading missions of many countries all over the world. Adger et al. (2003) and Kurukulasuriya and Mendelson (2008) agree that adaptation is one of the policy options that helps reduce the negative impact of climate change and build up resilience.

Adaptation could be classified into two main groups: public adaptation and private adaptation. Public adaptations go along with governmental policies and investment while private ones accompany households. Most previous studies related to the climate change adaptation in HCMC are concentrated on public investment such as infrastructure, 
planning, and macroeconomic management. In a recent report of Asian Development Bank in 2010 with respect to the adaptation to climate change in HCMC, some forms of risk from urban flooding and related public investment have also been addressed.

However, there are still many unknowns from the behavior of households in employing adaptive plans to cope with urban flooding. Some research found that in developing countries, physical resources and technology are limited, budget is constrained, and public adaptation could hardly meet the goals (Adger et al., 2003). So, individual alternative investments play an important role in the socialized way to deal with these natural problems.

There are a few studies that clearly project a complete assessment on household adaptation in Vietnam. This study is to provide more detailed scientific evidence of these problems at the household level in HCMC as regards the urban flooding problems. Similar policy implications are also provided. While most policy decisions related to climate change adaptation, including urban flooding in HCMC, have been set up from the supply side, i.e. what infrastructure should be built, this study provides policy makers with another view along with the demand-side evidence at the household level for policy making process, which is expected to fill the gap in their policy making toward urban flooding, including household's adaptive behavior.

A proper understanding of the capacity, methods, and value of various kinds of investment to adapt to flooding will help local authority develop a balanced policy to support and promote these strategies.

Local government has concentrated much effort on several projects to fight with urban flooding in HCMC for more than 10 years. However, the efficiency of these projects is doubted to be limited. Although local authorities have firmly committed to no more serious flood or inundation in five or seven years, the problem is still present in several places in Ho Chi Minh City. While waiting for an improved circumstance, households themselves find their own strategies to cope with flood risks. Moreover, when the economic growth has decelerated, public investment is delayed, and its efficiency is somehow affected. Therefore, household's adaptive investment to small local areas around their living places is considered as one of the important sources of adaptation. This study is also expected to provide policy-makers with research-based and demand-side evidence on how households in HCMC conducted their investments and its drivers in adapting to flooding in the city.

\section{Literature review}

In Vietnam, the weather conditions would be possibly more extreme and unpredictable (Chaudhry \& Ruysschaert, 2007), especially in case of flooding (Garschagen, 2010). Low capacity to cope with flood and pollution due to flood-prone living conditions, poverty, and lack of awareness of the changing variability and water pollution make people more vulnerable (Tran \& Nitivattananon, 2010). Suffer from environmental change could be 
considered as "social vulnerability," the exposure of people to stress as a result of its impacts or disruption to livelihoods and loss of security (Adger et al., 2001).

Adger et al. (2003) and Kurukulasuriya and Mendelson (2008) agree that adaptation is one of the policy options that helps reduce the negative impact of climate change and build up resilience. Adaptation refers to the adjustment to natural or human systems in response to actual or expected climatic stimuli or their effects, which moderates harm or exploits beneficial opportunities (IPCC, 2001a). In other words, adaptive capacity and investment implies factors that have the potential to reduce climate change-induced damages and/or increase household benefits.

Assessing adaptive capacity mostly involves identifying the factors that contribute to our capacity to adapt, and our ability to use these when needed. The concept of adaptive capacity focuses on the need for continuous flexibility and risk management, rather than looking for 'solutions' (Beckman, 2011). Nelson et al. (2007) also consider adaptive capacity to change and shocks in terms of the characteristics that facilitate flexibility in resource use, such as diversity of livelihood options and decision-making structures. These focuses are on preconditions, which help increase the ability to adjust to and deal with change.

There is also a need to clarify the differences between household's adaptation strategy and government's public policies, in which lower level adaptations are based on multiple sources of security while the higher the level of approaches, the more sectorial and technical the ways (Thomalla et al., 2006). Principles which are applied to adaptation demand access to a range of alternative resources in order to manage losses as the environment to which people adapt is imbued with frequent disasters and high-production risk. Coping and recovery plans on urban flooding are also developed based on these similar principles.

Adaptive capacity is classified into two cases: objective and perceived. Objectiveness approach are drives along with household resources (IPCC, 2001b), such as income, human and social capital, socio-economic characteristics (poverty, education, health, economic diversification, etc.), sanitation for special groups (ethnic, women, children, migrant, urban population, etc.). Alternatively, perception approach consists of drives including awareness and psychological response from household (Grothmann \& Patt, 2005).

Several studies discussed possible determinants of adaptation to climate change such as Fankhauser et al. (1999), Arnell and Delaney (2006), Berkhout et al. (2006) and Bleda and Shackley (2008). Some factors are external, including the development of new technologies, levels of government funding, linking forms of social capital that facilitate access to ideas and opportunities, cultural values, policies and governance processes, economic wealth, information and skills, infrastructure, institutions, and equity (Nelson et al., 2010). Several factors are considered internal such as risk perceptions, self-efficacy beliefs, and perceived adaptation costs (Grothmann \& Patt, 2005).

According to Brooks and Adger (2005), when considering the adaptive capacity, the first key to enhancing adaptive capacity is from both historical climate data and data from scenarios of future climate change, and another essential source is information on socio- 
economic systems, including both past and possible future evolution. Brooks and Adger (2005) also suggested resource requirement for implementing adaptation strategies including financial capital, social capital (e.g., strong institutions, transparent decisionmaking systems, formal and informal networks that promote collective action), human resources (e.g., labour, skills, knowledge and expertise), and natural resources (e.g., land, water, raw materials, biodiversity).

Another perspective proposed by Fankhauser et al. (1999) states that adaptation depends on three elements: the recognition of the need to adapt, an incentive to adapt, and the ability to adapt. It can be argued that the awareness of possible climate change effects that need adapting is the initial determinant of adaptation. "Without awareness, there will be no concern, and without concern, there will be no adaptation" (Arnell \& Delaney, 2006).

In recent years, flood-risk management has shifted from a primarily objective approach to an integrated approach that concentrates not only on investments in flood-prevention infrastructure such as dikes, but also on the alleviation of potential flood-damages by adopting private adaptation measures such as improving flood preparedness and response. Flood risks are likely to be reduced when private mitigation measures are undertaken because these strategies are expected to cut down flood damages for an individual household once it happens (Kellens et al., 2013). Flood risk perception is considered as a dominant factor that drives private mitigation behaviors (Bubeck et al., 2012).

Although it is expected that higher risk perception would more likely lead to private protection measures, this statement is not consistently supported by the majority of studies (Bubeck et al., 2012, Kellens et al., 2013). In particular, these studies find no or only a statistically weak relation between flood risk perceptions and mitigation behavior. Empirical evidence shows that whether a high-risk perception leads to a desired protective behavior depends on the level of flood-coping appraisals (Bubeck et al., 2012).

In addition to risk perceptions, fear of future flooding, components of coping appraisals, and flood experiences, flood mitigation behavior could be influenced by other factors such as knowledge about flood hazards, socioeconomic and geographical characteristics, barriers to private mitigation, and social environment (Bubeck et al., 2012).

When facing a risk, individuals are free to find ways to adapt to their situation. Since adaptation affects the costs and benefits of mitigation, their adaptive responses must be counted in projects when policy makers choose an optimal level of mitigation (Kane \& Shogren, 2000). In order to reduce the likelihood of damage caused by flooding, households tend to invest resources in reducing unwanted bad luck. Economic circumstances, the way people perceived risk, and the relative costs and benefits of alternative risk reduction strategies and relative wealth are most considered influential determinants of household's choice in risk reduction.

In that case, adaptation could be regarded as a self-insurance problem. Given a public mitigation, a household will try to maximize their expected utility $(E U)$ by deciding how much they will spend for the adaptation investment $x$ : 


$$
\max _{x_{i}} E U_{i} \equiv p U_{i}\left[Y_{i}-D\left(e, x_{i}\right)-c\left(x_{i}, z_{i}\right)\right]+(1-p) U_{i}\left[Y_{i}-c\left(x_{i}, z_{i}\right)\right]
$$

where:

$p$ is the probability that flooding occurs;

$e$ is the environmental severity;

$Z$ and $Y$ is the household's adaptive capacity and the initial wealth;

$D($.$) is the net damage from flooding;$

and $c($.$) is the cost of adaptation.$

The more adaptive capacity is built up, the lower damage they will bear when the bad state happens, which means $D_{x}<0$, while adaptation cost is assumed to be increasing $c_{x}>$ 0 . The adaptive capacity is assumed to be a function of the household characteristics $z_{i}=$ $h\left(s_{i}\right)$. Considering all of them as a whole, household will try to maximize their $E U$ by choosing an optimal level of adaptation $x^{*}=x\left(s_{i}, e\right)$.

We assume that the functional form of $x$ is linear in the explanatory variables and that the error term $\varepsilon_{i}$ is identically and independently distributed as the normal distribution over the population:

$$
x_{i}=\alpha+\sum \beta_{j} s_{i j}+\varepsilon_{i}
$$

Housing is one of the most important properties of a family, especially in urban areas. Therefore, most households try to protect them. In the case of flooding, examples of household flood risk reduction measures include internal and external to the structure, including planning approaches (Duží et al., 2015). Internal measures are changing floor material on the ground floor to be water resistant; elevating the ground floor or having garages or simple cellars as the ground floor; installing mobile window and door flood barriers; using materials and finishes that are water resistant; designing and constructing to withstand flood forces and energies; purchasing contents and property insurance against flood, damage, as well as other perils; using information from external local forecasting and warning systems; formulating and testing household evacuation plans; moving valuables on upper floors in case of flood occurrence. On the other hand, external measures are identified as not building in flood-prone areas; implementing hydro-isolation of the walls to avoid water contact in inundated ground; implementing water drainage systems around the house that can be as simple as basic landscaping and as complex as engineered yards and drives including some or all of drainage pipes, gravel, sewers, earthworks, slopes, and retention basins; or having personal meteorological and hydrological stations. Lasage et al. (2014) study the effectiveness of flood adaptation in HCMC. They find that several typical adaptations include ringing the dike, wet-proofing and dry-proofing, or elevating roads or building. Using indicators within technical evaluation, they show that the adaptation strategies such as wet-proofing and dry-proofing generate the best results. 


\section{Methodology}

An investigation into household investment adaptive to flooding in HCMC is also included by exploring various choices of household investment against that problem, including their decisions and their cost. We use Preventive Cost Method to estimate value of the flooding impacts on households in HCMC. We have also evaluated the effectiveness of their investments in a general model about vulnerability proposed by Adger (1997) and a specific model proposed by Brouwer et al. (2009).

A multinomial logit model has been used to test the probability that a household would spend money on each type of measures to protect their house.

$$
\operatorname{Prob}\left(\text { invest }_{\text {type }}=j\right)=\frac{e^{X \beta_{j}}}{\sum e^{X \beta}}
$$

where $X$ is a vector of independent variables related to their socio-economic characteristics, their experience with flood, and their adaptive capacity while $\beta$ is the vector of regression coefficients.

The odd ration is defined as:

$$
\Omega_{i \mid j}=\frac{\operatorname{Pr}(y=i \mid X)}{\operatorname{Pr}(y=j \mid X)}=\frac{e^{X \beta_{i}}}{e^{X \beta_{j}}}
$$

The regression coefficients are calculated using the maximum likelihood method.

For data sampling, 461 households have been randomly surveyed in six districts of HCMC, including high-frequently flooded districts (consisting of Binh Tan, Binh Thanh), moderately flooded (Tan Phu, District 6) and less-occurrence areas (Go Vap, District 8). The number of flooding points is visualized by Tuoi Tre Online based on a report from Steering Centre for Urban Flood Control Program (TTO, 2015). In each district, two wards were randomly surveyed.

Tan Phu District is about 16 kilometers squared, with a density of 26,104. Established from 2003 (separated from a big district, Tan Binh), along with an increase of population, this district also faces many flooding problems. Until 2015, there are about five frequently deep-flooded prone locations in this area.

Binh Tan is adjacent to Tan Phu and is considered as one of the most severe flooded districts in HCMC. This district is about 51.89 kilometers squared with a lower density compared to other districts $-11,778$. However, the number of flood prone here is just second to Binh Thanh District. District 6 and District 8 are close to Binh Tan District. These places had severe flooded problems a decade ago and their situations have been improved significantly recently. The number of flood prone areas has decreased to an acceptable level. 


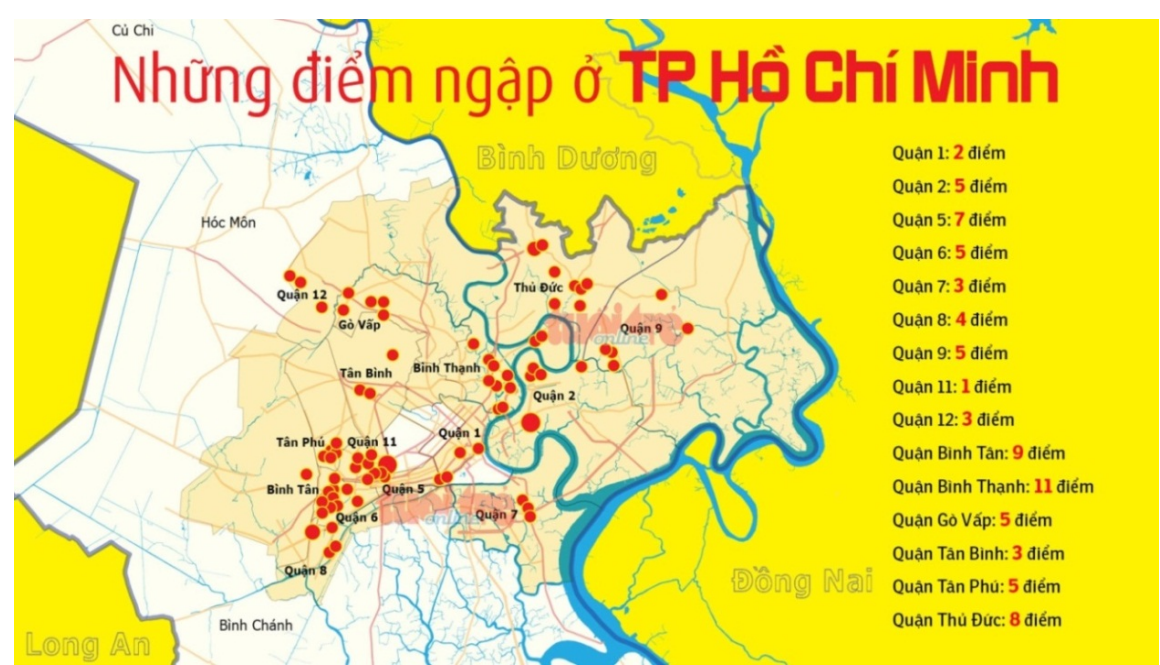

Figure 1. Red dots: Frequently flooded locations in Ho Chi Minh City (TTO, 2015)

Binh Thanh is impacted most by inundation because it is close to rivers and canals. Every time when it is raining, or even just a tide, many places would be flooded. A tide combined with a rain could result in severe flood in some prone areas from 0.1 to 0.5 meters.

Next to Binh Thanh is Go Vap District, the highest elevation place in Ho Chi Minh City. A decade ago, flooding almost never occurred in this district. In recent years, however, the high tide and sewage problem has made inundation popularly troublesome.

\section{Data description and analysis}

\subsection{Descriptive analysis}

This part presents the result of the descriptive statistics of some important variables in the collected data sample.

\section{Table 1}

Social characteristics

\begin{tabular}{lcc}
\hline & Mean & Std. Dev. \\
\hline Gender (male) & 0.44 & 0.50 \\
Age & 41.49 & 12.31 \\
$19-24(06.38 \%)$ & 21.17 & 1.94 \\
$25-35(30.85 \%)$ & 31.00 & 2.96 \\
$36-60(53.19 \%)$ & 45.90 & 7.08 \\
Years of education & 10.59 & 3.53 \\
Years living in HCMC & 19.55 & 13.26 \\
\hline
\end{tabular}

First, the percentage of male in the sample is $43.61 \%$. From the data, the average age is 41.49 , and $6.38 \%$ of the sample has age ranged in $16-24,30.85 \%$ in the $25-35$, and $46.80 \%$ in 
the range of 36-60. They have spent on average 10.59 years at school; particularly $23.40 \%$ of the respondents have studied at higher education institutions.

In the urban area, it is a difficult to interview local people since they work all weekdays and mostly refuse to join in a face-to-face interview at the weekend or in the evening, which affects our sampling. $65.43 \%$ of the respondents are self-employed, while $10.64 \%$ are doing the housework. Only $11.70 \%$ of the sample are employees working for salary.

\section{Table 2}

Employment status

\begin{tabular}{lcc}
\hline & Percentage & Cumulative Percent \\
\hline Employed & 11.7 & 11.7 \\
Self-employed & 65.43 & 77.13 \\
Entrepreneur & 0 & 77.13 \\
Students & 5.85 & 82.98 \\
Housework & 10.64 & 93.62 \\
Other & 0.53 & 94.15 \\
Unemployment & 0.53 & 94.68 \\
Out of labor force & 5.32 & 100 \\
\hline
\end{tabular}

Many of them have been living in Ho Chi Minh City for a long time, on average 19.55 years, $73.4 \%$ residing in the city for more than 10 years.

For those who live in semi-concrete houses, their income is about 5.41 million VND per capita per month (11.28 million per household per month, over 2.25 people) while people living in concrete houses have higher income of 7.29 million VND per capita per month (16.62 million per household per month, over 2.44 people). For a general analysis, this average value is lower than the city's reported value, and so is the income per capita. This is due to the nature of observations; it is difficult to access and interview high-income family in the urban areas, and most importantly, the tendency to understate their income of the respondents. However, $56.63 \%$ of the households receive income of over 10 million VND per month, which is a good reflection of the proportion of the households with medium income in HCMC.

\section{Table 3}

Living condition

\begin{tabular}{lccccc}
\hline & Percentage & $\begin{array}{c}\text { Mean } \\
\text { Income }\end{array}$ & $\begin{array}{c}\text { Std. Dev. } \\
\text { Income }\end{array}$ & $\begin{array}{c}\text { Mean } \\
\text { Area }\end{array}$ & $\begin{array}{c}\text { Std. Dev. } \\
\text { Area }\end{array}$ \\
\hline House type & & & & & \\
$\quad$ Semi-concrete & 34.58 & 5.41 & 1.98 & 38.93 & 19.75 \\
Concrete & 64.89 & 7.29 & 4.71 & 60.09 & 47.29 \\
Temporary & 1.53 & 6 & 0 & 32 & 0 \\
House ownership & 37.77 & 6.54 & 3.97 & 47.48 & 41.29 \\
$\quad$ Private & 62.23 & 6.69 & 4.14 & 55.55 & 40.7 \\
Total & 100 & 6.63 & 4.06 & 52.51 & 40.89 \\
\hline
\end{tabular}


The average area of the land occupied by the residents is 52.51 meter squared and the usable living area is about 95.57 meter squared. $62.77 \%$ are private-owned houses while $37.23 \%$ are rented.

$63.83 \%$ of them have been affected by flood in the recent 5 years, $93.54 \%$ of them are really concerned about the flood-related problems, $69.56 \%$ believe that the situation could be improved in the near future, $22 \%$ of them had changed the living location due to flood, and most of them, $96.23 \%$ were in serious trouble when facing flood in HCMC (4.07 over 5 scale).

They are all dreadfully worried about the flooding situation and climate change. 3.86 over 5 think floods will happen more frequently, 4.05 over 5 consider high severity, and 4.45 over 5 are merely apprehensive about it.

\section{Table 4}

Flooding experience and reasons

\begin{tabular}{lc}
\hline & Percentage \\
\hline Experience and preparedness & 63.83 \\
Affected by a flood in 5 years & 69.56 \\
Flooding situation possibly improved & 93.54 \\
Concerned about consequences from flooding & 22.00 \\
Changed living location because of inundation & 96.23 \\
Had trouble with flood & \\
Concerns about main reasons for flood & 12.50 \\
Rainfall & 64.17 \\
Tidal level & 20.83 \\
Drainage & 2.50 \\
Other & \\
\hline
\end{tabular}

Considering the attitudes toward the risk of natural disaster, flooding is of great concern, followed by typhoon and abnormal temperature before thunderstorm and earthquake.

About the social risk problem, flood is not high concerned. Living in HCMC, they pay more attention to the risks involved with robberies, traffic accidents, fires, and then floods and congestion.

\section{Table 5}

Relative concerns

\begin{tabular}{lcc}
\hline & Mean & Std. Dev. \\
\hline Disaster & & \\
Flood & 1.93 & 1.2 \\
Typhoon & 2.99 & 1.18 \\
Earthquake & 3.82 & 1.45 \\
Thunderstorm & 3.28 & 1.26 \\
Temperature & 2.99 & 1.29 \\
Social problems & &
\end{tabular}




\begin{tabular}{lcc}
\hline & Mean & Std. Dev. \\
\hline Robbery & 2.25 & 1.17 \\
Traffic accident & 2.76 & 1.1 \\
Fire & 3.08 & 1.45 \\
Flood & 3.11 & 1.33 \\
Congestion & 3.79 & 1.52 \\
\hline
\end{tabular}

$25.78 \%$ of them usually check or get information related to flood risk to prepare for an adaptation. TV and Internet are the two main sources for them to get information related to weather and risk related to flooding, with respect to 60 and 40 percent.

\section{Table 6}

Concerns and belief related to urban floods

\begin{tabular}{lcc}
\hline & Avg. Scale & Std. Dev. \\
\hline Concerns & 3.86 & 1.29 \\
Frequency & 4.05 & 1.90 \\
Severity & 4.45 & 0.87 \\
Worriedness & 4.08 & 1.02 \\
Troublesome & & \\
Belief & 3.54 & 1.48 \\
Households have ability to reduce & 4.25 & 1.20 \\
All residents need solidarity & 4.66 & 0.80 \\
It's the government responsibility & 3.44 & 1.47 \\
Flood mitigation could be effective & 3.71 & 1.36 \\
People could change daily habit to adapt & 3.33 & 1.57 \\
Flooded situation would be solvable & & \\
\hline
\end{tabular}

A little more than the neutral, respondents less confidently think that their family could find at least one measure to protect themselves from flooding problem (3.54 over 5). Most of them highly believe government should be the main actor in the fight against this flooding problem in HCMC (4.66) and suggest all sectors together should cooperate to control and mitigate it (4.25). A moderate number of respondents agree that they should change their daily routine activities to adapt to the current flooding situation in HCMC (3.71 over 5).

Only $22.58 \%$ know that the city has public project that helps reduce flooding. However, they scarcely think those projects are fully effective. Only $8.4 \%$ have directly contributed an average amount of $312,000 \mathrm{VND}$ to public projects when the local people committee came for request. 


\section{Table 7}

Information related to flooding prevention measures

\begin{tabular}{lcc}
\hline & Mean & Std. Dev. \\
\hline Got information & 0.26 & 0.49 \\
Radio & 0.10 & 0.32 \\
TV & 0.60 & 0.52 \\
Internet & 0.40 & 0.52 \\
Known a public project & 0.23 & 0.42 \\
Effectiveness & 3.52 & 1.08 \\
Contribution & 312,500 & 433,905 \\
\hline
\end{tabular}

\subsection{Household investment and measures}

There are two main methods applied to protect houses from inundation, floor elevation, and dry-proofing (to protect water from flowing inside). The other minor method is wetproofing (buying and applying materials to strengthen their houses but still letting the water flow through their house when flood happens. This method could be considered almost doing nothing since the cost is tiny and hard to differentiate.

\section{Table 8}

Investment methods

\begin{tabular}{lccccc}
\hline & Percentage & Mean & Std. Dev. & Min & Max \\
\hline Elevation & 28.72 & $1,493,985$ & $3,477,476$ & 162,500 & $18,200,000$ \\
Effectiveness & & 3.70 & 1.38 & 1 & 5 \\
Dry-proofing & 14.89 & 924,357 & $1,445,224$ & 42,000 & $5,000,000$ \\
Effectiveness & & 3.64 & 1.15 & 1 & 5 \\
Wet-proofing & \multirow{2}{*}{8.24} & 150,000 & 239,791 & 50,000 & 500,000 \\
Effectiveness & & 2.8 & 1.79 & 1 & 5 \\
\hline
\end{tabular}

$28.72 \%$ of the households have elevated their floors to protect against flood and $2 / 3$ of them considered that solution highly effective. The remaining proportion said that though they tried to elevate their floor, but the height of the street kept increasing so that sometimes their resolutions became less effective. The cost of floor elevation is about 1,493,985 VND per meter square at the 2015 price level, after being adjusted for inflation.

$14.89 \%$ applied dry-proofing for their houses. This method is much cheaper than elevation at about 924,357 VND per house or 21,050 VND per meter square, and their effectiveness is just in the middle scale. Wet-proofing is even cheaper because they do not have to invest in anything much related to construction, just to relocation of important facilities inside their house.

$17.50 \%$ of them had financial difficulty when investing in measures to protect their houses from flooding: $30.77 \%$ tried to get a loan while others borrowed from friends or 
relatives. The range of loan is from 10 million to 50 million VND at an unofficial rate of $2 \%$ per month, nearly double in comparison to the loan from the banks.

We have interviewed 461 households with regard to the investment method(s) they have applied to fight against the flooding situation they faced in the past and would be concerned about in the future. The method they shared with us was based on the real situation they invested during their living in their particular places. Among 461 households, only 269 observations are used for the model after deselecting some of those who are living in rented apartments, or those whose wards have never had a flooding problem, or the respondents who know much about their family investment decisions.

Since there is no significant difference in the way people decide between wet-proofing and doing nothing, these two categories have been combined into one as the reference option.

\section{Table 9}

Estimation results

\begin{tabular}{|c|c|c|c|}
\hline Measures & Variables & Coefficient & S.E \\
\hline \multirow[t]{12}{*}{ Elevation } & Age & $0.3102^{* *}$ & 0.1464 \\
\hline & Age squared & $-0.0028^{*}$ & 0.0014 \\
\hline & Male & -0.8756 & 0.5765 \\
\hline & Schooling & 0.0137 & 0.0834 \\
\hline & Income & $-0.0481^{*}$ & 0.0259 \\
\hline & Land area & $0.0261^{* * *}$ & 0.0082 \\
\hline & Flood-prediction & $0.6174^{*}$ & 0.3365 \\
\hline & Flood-prediction squared & $-0.0674^{* *}$ & 0.0324 \\
\hline & Years of living in HCMC & $-0.0125^{*}$ & 0.0079 \\
\hline & Flood-experience & $0.3284^{* * *}$ & 0.0675 \\
\hline & Flood-experience squared & $-0.0052^{* * *}$ & 0.0012 \\
\hline & Public investment & -0.0401 & 0.1413 \\
\hline \multirow[t]{12}{*}{ Dry-proofing } & Age & $0.2127^{* *}$ & 0.1000 \\
\hline & Age squared & $-0.0027^{* *}$ & 0.0011 \\
\hline & Male & 0.5288 & 0.4430 \\
\hline & Schooling & -0.0604 & 0.0632 \\
\hline & Income & $-0.0540^{* * *}$ & 0.0173 \\
\hline & Land area & -0.0026 & 0.0082 \\
\hline & Flood-prediction & 0.0181 & 0.0240 \\
\hline & Flood-prediction squared & -0.0001 & 0.0002 \\
\hline & Years of living in HCMC & -0.0082 & 0.0059 \\
\hline & Flood-experience & 0.0675 & 0.0621 \\
\hline & Flood-experience squared & -0.0007 & 0.0012 \\
\hline & Public investment & 0.3572 & 0.3055 \\
\hline
\end{tabular}

Wet-proofing (Base)

Note: ${ }^{*},{ }^{* *}$ and ${ }^{* * *}$ denote significance at $10 \%, 5 \%$ and $1 \%$ respectively 


\section{Table 10}

Marginal effects of investment decisions

\begin{tabular}{lccc}
\hline & $\begin{array}{c}\text { Wet-proofing } \\
(66.91 \%)\end{array}$ & $\begin{array}{c}\text { Elevation } \\
(16.73 \%)\end{array}$ & $\begin{array}{c}\text { Dry-proofing } \\
(16.36 \%)\end{array}$ \\
\hline Age & $-0.0378^{* * *}$ & $0.0173^{*}$ & 0.0204 \\
Age squared & $0.0004^{* * *}$ & -0.0001 & $-0.0002^{*}$ \\
Male & -0.0158 & $-0.0793^{*}$ & $0.0951^{*}$ \\
Schooling & 0.0059 & 0.00264 & -0.0085 \\
Income & $0.0081^{* * *}$ & -0.0021 & $-0.0060^{* * *}$ \\
Land area & -0.0009 & $0.0020^{* * *}$ & -0.0010 \\
Flood-prediction & $-0.0312^{* *}$ & $0.0454^{* *}$ & -0.0141 \\
Flood-prediction squared & $0.0032^{* *}$ & $-0.0050^{* *}$ & $0.0018^{* *}$ \\
Years of living in HCMC & $0.0014^{*}$ & -0.0007 & -0.0007 \\
Flood-experience & $-0.0229^{* * *}$ & $0.0226^{* * *}$ & 0.0003 \\
Flood-experience squared & $0.0003^{* *}$ & $-0.0003^{* * *}$ & 0.0000 \\
Public investment & -0.0368 & -0.0126 & 0.0494 \\
\hline
\end{tabular}

Note: ${ }^{*}{ }^{* *}$ and ${ }^{* * *}$ denote significance at $10 \%, 5 \%$ and $1 \%$ respectively

A majority of people living in Ho Chi Minh City have decided to do nothing when facing flooding problems. Regarding the age of household heads, older people tend to be familiar with the situation and do nothing while younger people will be more likely to switch to another method, such as dry-proofing. On the gender analysis, males tend to reduce their incentive to elevate the house in comparison with the female, at about $7.93 \%$.

Elevating the house is one of the considerable methods, but it is expensive. Only $16.73 \%$ of the households surveyed applied this costly method. The area of the land to elevate, together with flood experience and prediction of what could happen in the future, is significant to be considered. Specifically, when they faced the higher inundation in the past and/or predicted the higher likelihood that the flood would be around their house, they will more possibly choose to elevate it rather than doing nothing, either dry- or wetproofing. However, the probability does not keep increasing but abates after reaching a point.

On another side, years of schooling has no statistically significant impact on investment decisions, but the land area does not reach a not-so-high level of probability.

Dry-proofing is also a temporary method to apply, which accounts for $16.36 \%$ of household investment decisions. This decision is based on income, flooding prediction, and age rather than any other factors. However, at the higher age range, probability of investment in this method goes down while prediction comes with a positive correlation. 
Wet-proofing reflects almost the same results as doing nothing, except for the fact that the family has already relocated or rearranged the facilities inside the house and has been ready to cope with water flowing through and surrounding it. Years of living in the city and experience toward floods around their house significantly affect the trade-off between applying this method and others.

Why do a majority of household accept doing nothing rather than elevating their floor? An explanation is that they do not feel certain about the improvement of the situation. Among observations that indicate that the family had been flooded at least once, or prediction that there would be more floods, relying on the public investment is the main reason for their answers. Another obvious answer from the estimation in this multinomial logit model is the difference in the level of income per capita.

Finally, public investment does not alter the decision of people living in inundation areas. Dry-proofing could somehow be considerable, but not significant. The reason could be they have been facing the situation for years and seen nothing change clearly. A costly investment could be of no efficiency whatsoever.

\section{Conclusion}

Flooding in Ho Chi Minh City has grown as an alarming problem. Most people recognize the trouble arising from inundation, cost of damage, time of travelling, health issues, and so on. It is not because of climate change, but the main reason why residents in HCMC claim for flooding is the draining system. Although the city has invested in several public projects to control the tide, local people reckon that they are not totally effective. Private investment is considered for a small number of households. Since most believe that the local authorities must be responsible for controlling the flooding problem, people in the city are less likely to invest a big money in feasible measures to protect their house from flooding. The uncertainty about the future situation, income, and the cost of investment are subject to their reduced incentive to apply flood controlling methods.

Making a private investment to cope with flooding damage is one of the big issues to which all households pay attention. Private measures include ground elevation, dryproofing, and wet-proofing. Since the cost of elevation is found to be high, along with the uncertainty of the effectiveness of public projects and concerns over abnormal weather conditions, a majority of people chose wet-proofing or do-nothing alternative. Some families decided to elevate their houses, while other people make an effort to protect their houses by using tools and materials to prevent water from flowing in, or opting for a higher-level location to live within. The more experience and/or the firmer the prediction of the flooding level, the more likely they tend to elevate their houses, but in a small range. If the inundation level keeps increasing, they chose to peacefully live with floods when the effectiveness of any method or project is still doubtful. 
Many local people complain about the effectiveness of the urban drainage units and feel uncertain about the effectiveness of public investment regarding solutions to the flooding situation in Ho Chi Minh City. Their adaptation measures have come with no significant concerns as to whether other public investments have been made or not. Moreover, in the event of high rainfall or high tides, workers-in-charge are usually late to help control the situation. Viable recommendations include, but are not limited to, cleaning the sewage often, especially right before the rainy season and in the months when high tides frequently occur

\section{References}

Adger, N., Kelly, M. and Ninh, N. H. (2001). Living with Environmental Change. Social Vulnerability, Adaptation and Resilience in Vietnam. Routledge, London, UK, and New York, NY, USA.

Adger, W., Huq, S., \& Hulme, M. (2003). Adaptation to Climate Change in the Developing World. Progress in Development Studies, 3, 179-195.

Arnell, N.W., Delaney, E.K., (2006). Adapting to climate change: public water supply in England and Wales. Climatic Change, 78, 227-255.

Asian Development Bank (ADB). (2010). Ho Chi Minh City Adaptation to Climate Change. ADB Publishing.

Beckman, M. (2011). Converging and conflicting interests in adaptation to environmental change in central Vietnam. Climate and Development, 3(1), 32-41

Berkhout, F., Hertin, J., \& Gann, D. M. (2006). Learning to adapt: organisational adaptation to climate change impacts. Climatic Change, 78, 125-156.

Bleda, M., Shackley, S., (2008). The dynamics of belief in climate change and its risks in business organisations. Ecological Economics, 66, 517-532.

Brooks, N. and Adger, N. (2004) Assessing and Enhancing Adaptive Capacity: Technical Paper 7. New York: UNDP

Brouwer, R., Akter, S., Haque, L., \& Haque, E. (2007). Socioeconomic Vulnerability and Adaptation to Environmental Risk: A Case Study of Climate Change and Flooding in Bangladesh. Risk Analysis, 313-326.

Brouwer, R., Akter, S., Brander, L., \& Haque, E. (2009). Economic valuation of flood risk exposure and reduction in a severely flood prone developing country. Environment and Development Economics, 14(03), 397.

Bubeck, P., Botzen, W. J. W., \& Aerts, J. C. J. H. (2012). A Review of Risk Perceptions and Other Factors that Influence Flood Mitigation Behavior. Risk Analysis, 32(9), 14811495.

Chaudhry, P., Ruysschaert, G. (2007) Climate Change and Human Development in Viet Nam: A case study for the Human Development Report 2007/2008.

Dao, X. H. (2009). Reasons and Solution for HCMC Inundation. Journal of Water Resources and Environmental Engineering, 24, 3-6.

Duží, B., Vikhrov, D., Kelman, I., Stojanov, R., \& Juřička, D. (2015). Household measures for river flood risk reduction in the Czech Republic. Journal of Flood Risk Management,

Fankhauser, S., Smith, J., \& Tol, R. (1999). Weathering climate change: some simple rules to guide adaptation decisions. Ecological Economics, 30, 67-78.

Garschagen, M. (2010): Predicting Future Vulnerabilities to Climate Change Impacts in Vietnam - The Challenge of Capturing Dynamic Pathways Under Conditions of Transformation.- 
6th Conference of the European Association for South East Asian Studies, EUROSEAS, 26-28 August 2010, Gothenburg, Sweden

Grothmann, T., \& Patt, A. (2005). Adaptive Capacity and Human Cognition: The Process of Individual Adaptation to Climate Change. Global Environmental Change, 15, 199-213.

Intergovernmental Panel on Climate Change (IPCC) (2001a). Climate Change: The Scientific Basis. The Contribution of Working Group I to the Third Scientific Assessment of the Intergovernmental Panel on Climate Change. Cambridge: Cambrige University Press.

Intergovernmental Panel on Climate Change (IPCC) (2001b). Impacts, Adaptation and Vulnerability. The Contribution of Working Group II to the Third Scientific Assessment of the Intergovernmental Panel on Climate Change. Cambridge: Cambrige University Press.

Kane, S., \& Shogren, J. (2000). Linking Adaptation and Mitigation in Climate Change Policy. Climatic Change, 45(1), 75-102.

Kellens, W., Terpstra, T., \& De Maeyer, P. (2013). Perception and Communication of Flood Risks: A Systematic Review of Empirical Research. Risk Analysis, 33(1), 24-49.

Kurukulasuriya, \& Mendelsohn. (2008). A Ricardian analysis of the impact of climate change on African cropland. African Journal of Agricultural and Resource Economics, 1-23.

Lasage, R., Veldkamp, T. I. E., de Moel, H., Van, T. C., Phi, H. L., Vellinga, P., \& Aerts, J. C. J. H. (2014). Assessment of the effectiveness of flood adaptation strategies for HCMC. Natural Hazards and Earth System Science, 14(6), 1441-1457.

Mendelsohn, R. (2000). Efficient adaptation to climate change. Climate change, 45, 583-600

Nelson, D., Adger, N., and Brown, K., (2007). Adaptation to environmental change: contributions of a resilience framework. Annual Review of Environment Resources, 32, 395-419.

Nelson, R., Kokic, P., Crimp, S., Martin, P., Meinke, H., Howden, S. M., and Nidumolu, U. (2010). The vulnerability of Australian rural communities to climate variability and change: Part II - Integrating impacts with adaptive capacity. Environmental Science and Policy, 13(1), 18-27

Nguyen, D. D. (2011). Inundation in HCMC: a 'soft' approach. Retrieved September 14, 2015, from Vietnam Urban Planning and Development Association - VUPDA: http:/ / ashui.com/mag/tuongtac/ phanbien/4272-ngap-lut-tai-thanh-pho-ho-chiminh-huong-tiep-can-mem.html

Steering Centre for Urban Flood Control Program. (SCFC) (2013). Ho Chi Minh Flood and Inudation Project Final Report.

Tuoi Tre Online (TTO) (2015). 66 Inundation locations in Ho Chi Minh City. Retrieved from https:/ / tuoitre.vn/ di-duong-sai-gon-khi-mua-lon-nho-ky-66-diem-nay973795.htm

Thomalla, F., Downing, T., Spanger-Siegfried, E., Guoyi Han, and Rockstrom, J., (2006). Reducing hazard vulnerability: towards a common approach between disaster risk reduction and climate adaptation. Disasters, 30(1). 39-48

Tran, T., Nitivattananon, V., (2011) Adaptation to flood risks in Ho Chi Minh City, Vietnam. International Journal of Climate Change Strategies and Management, 3(1), 6173 